\title{
Cancer Center Supplements
}

National Cancer Institute

\section{Source}

National Cancer Institute. Cancer Center Supplements. NCI Thesaurus. Code C19258.

To stimulate the development of resources and pilot projects in human cancer genetics. 